University of New Hampshire

University of New Hampshire Scholars' Repository

$1-1-1989$

\title{
Verbal Concepts as Abstract Structures: The Most Basic Conceptual Metaphor?
}

Sylvia Weber Russell

University of New Hampshire, Durham, swr@cs.unh.edu

Follow this and additional works at: https://scholars.unh.edu/compsci_facpub

\section{Comments}

This is an Author's Original Manuscript/Accepted Manuscript of an article published by Taylor \& Francis in Metaphor and Symbolic Activity in 1989, available online: https://dx.doi.org/10.1207/s15327868ms0401_4

\section{Recommended Citation}

Sylvia Weber Russell - Verbal concepts as abstract struc tures: The most basic conceptual metaphor? Metaphor and Symbolic Activity 4 (1), 55-60 (1989).

This Article is brought to you for free and open access by the Computer Science at University of New Hampshire Scholars' Repository. It has been accepted for inclusion in Computer Science Scholarship by an authorized administrator of University of New Hampshire Scholars' Repository. For more information, please contact Scholarly.Communication@unh.edu. 
Verbal Concepts as Abstract Structures:

The Most Basic Conceptual Metaphor?

Sylvia Weber Russell

Computer Science Department

University of New Hampshire

Durham, NH 03824

Published in "Metametaphorical Issues" forum,

Metaphor and Symbolic Activity, Vol. 4, No. 1 (1989)

Lawrence Erlbaum Associates, Inc. 
I read with interest George Lakoff's (1986) article "A Figure of Thought," which includes the recognition of some metaphor themes or "conceptual metaphors" (i.e., "constructed $O B J E C T^{\prime \prime}$ and "CONTAINER") that are instrumental to other conventional conceptual metaphors that he has identified, such as "IDEAS ARE FOOD" and "LIFE (or LOVE) IS A JOURNEY." The theory Lakoff discussed should draw attention within the area of artificial intelligence, because of what it says about metaphoric-knowledge organization. Of specific interest to me, however, is that his reference to the basic role of the "OBJECT" and "CONTAINER" metaphor themes is reminiscent of the spatially grounded abstract structures ${ }^{1}$ used in the MAP computational approach to metaphor analysis (Russell 1976, 1986). The MAP program, which roughly paraphrases syntactically simple, cross-modal input metaphors, is not yet integrated with certain aspects of metaphoric text processing at the higher level that is a focus of Lakoff's discussion. However, I believe that the program can be viewed as an illustration of potential answers to questions Lakoff raised about the role of basic conceptual metaphors such as "OBJECT" and "CONTAINER." The following comments expand this observation and relate the idea of basic conceptual metaphors to the question of verb representations in general.

Implementation of Lakoff's characterizations of metaphor by computational efforts is not new. His demonstration (see Lakoff \& Johnson, 1980) of the prevalence and systematic nature of certain metaphor themes in ordinary conversation has been exploited in a computational metaphor-understanding procedure (see Carbonell, 1982) directly utilizing Lakoff's metaphor themes. However, this approach did not address the theoretical and computational task of "getting inside" the process of metaphoric extension of verbs and nominals. This task entails a consideration of how the concepts salient to a metaphor are, at a symbolic level, transformed in the process of (human and computational) interpretation. With this focus, I missed in Lakoff's earlier work any attempt to explain the mappings involved in his conventional metaphors in terms of a deeper semantic analysis that may be applicable to unconventional metaphors as well. That is, there appeared to be no "bottom-up" analysis representing an attempt to identify the common ground between literal and metaphoric meaning.

In contrast to Lakoff's past work, his recent article does relate to this kind of analysis. His reference to the basic role of the "CONTAINER" and "OBJECT" metaphor themes gives a new context to representations used in MAP. MAP formalizes metaphoric common ground in terms of abstract verbal structures that underlie these and other metaphor themes. A state or resultant state underlying any verbal concept is represented as a structure predicating the existence of an OBJECT (the "constructed OBJECT" metaphor theme), the quality of an existing OBJECT, or the LOCATION of an object. The latter is a generalization of the "CONTAINER" metaphor theme: A person can be metaphorically viewed as being "in" or "at" a state and, alternatively, the state can be viewed as "within" or "having come to" a person. Examples are "build" for OBJECT existence (an object results) and "swallow" or "vacuum up" for LOCATION (an object enters a location).

The adoption of these low-level metaphoric structures can be thought of as an implemented generalization of Lakoff's expressed hypothesis that some metaphors, such as "OBJECT" and "LOCATION/CONTAINER," apparently must be in the human conceptual system for other metaphors to work. From the perspective of computational text understanding, these verb structures mediate the comprehension and paraphrase of a large class of linguistically expressed metaphors. This class includes not only linguistic instantiations of Lakoff's conceptual metaphors but also of isolated or unsystematic linguistic metaphor.

For example, MAP interprets the input metaphors "They swallowed the ideas" and "They vacuumed up the ideas" similarly, even though the former is an instance of the "IDEAS ARE FOOD" metaphor and the latter is not. The program does this by first recognizing the abstract locative relation (i.e., the "LOCATION" metaphor theme) defined in the lexicon or knowledge base as the resultant state underlying the literal senses of the verbs swallow and vacuum up. In both cases, the resultant state OBJECT BE-AT LOCATION represents the information that the main effect of swallowing is that the swallowed OBJECT is located at/in the swallower. This abstract locative relation can then be given an intermediate interpretation in the target

${ }^{1}$ The term abstract is used in a conventional rather than a strict sense in this discussion. 
domain, that is, the domain of the abstract object (idea), which is MENTAL. In the interpretation, the ANIMATE concept, they, maps into the "possessor" or "haver" of the abstract concept, idea. An English reading of the intermediate representation of the present example might then be, They (i.e., their minds) started to have mental objects (of unknown nature). A literal target-domain interpretation, representing a more complete transformation of source-domain terms, can be achieved through the choice of a target-domain verb, such as think, defined in the knowledge base as having an abstract structure that is found to match the result component of the input verb, namely OBJECT BE-AT LOCATION (mental objects are "located in" the mind). This might produce They started to think that... $\langle$ nature of idea $\rangle$. It can be seen from this example that the abstract structure, which reflects a basic conceptual metaphor, facilitates a mapping from a potentially rich metaphoric expression in which an action or state is treated as an object to a simpler literal expression in which the action or state is represented as a verbal concept.

A different example, used by Lakoff to illustrate interactions between certain conceptual metaphors, demonstrates further the fundamental role of the "LOCATION/CONTAINMENT" metaphor in language. Lakoff characterizes the statement "I am (thinking of) leaving the relationship" in terms of pieces of "folk knowledge" including the proposition that "an interpersonal relationship is a container." However, one could say more generally that any (?) verbal or attributive concept can be treated as a container or a location through the appropriate syntactic expression. For example, "We live in hope" also expresses metaphoric containment, yet hope does not share certain other aspects of a relationship as used in Lakoff's example. MAP handles all these examples consistently through the general assumption that the "LOCATION/CONTAINER" metaphor (as in "in hope"), is a means of linking people to abstract attributes and actions of any kind for the purpose of linguistic expression. For "I am leaving the relationship," the program finds that the literal sense of leave has the result component 'NOT (OBJECT BE-AT LOCATION). This time the OBJECT, $I$, rather than the LOCATION is ANIMATE, and therefore becomes the possessor in the intermediate representation of the result, which reads I no longer have the relationship / (e.g.) love, or literally, I no longer relate to/love....

If we turn from the "LOCATION/CONTAINER" metaphor to the "(constructed) OBJECT" metaphor, the abstract result structure for "We built our relationship" is OBJECT (= relationship) BE. The inclusion of we as the AGENT causing the resultant state gives the intermediate reading We caused our relationship to exist; the literal form might be, We started relating. A second type of "OBJECT" metaphor, with a focus on quality or attributes rather than construction, is illustrated by the example, "The relationship blossomed." Here, the intermediate form corresponds to The relationship changed in a positive way; the literal form might be Someone related to [?] better.

In this computational approach to text comprehension, then, interpretations are mediated by abstract verb structures hypothesized to underlie literal verbs and any target-domain terms approximated by metaphoric extensions of these verbs. These abstract representations, based on the "OBJECT" and "LOCATION/CONTAINER" metaphors, are not truly literal for the target domain of the input. As abstract metaphors, however, these representations can be thought of as partial transformations from source-domain terms to target-domain terms. At the same time, they categorize verbs across domains, and therefore play a fundamental organizing role in the computational interpretation of both conventional and unconventional linguistic metaphor. ${ }^{2}$ Given these basic metaphoric formulations of actions and states (i.e., the "VERBAL CONCEPTS ARE ABSTRACT STRUCTURES" metaphor), the program simply relates these to literal verbal or attributive forms. Converting abstract OBJECTs and LOCATIONs into literal verbs in the process of computer interpretations can be seen as the reverse of that preliminary step of metaphor creation that, for example, makes "objects" of "thinking" or "loving" so that these concepts, realized syntactically as nouns, can be "swallowed," can "drift," and so on. It is at the level of language representation itself, then, that the MAP implementation can be seen as a generalization of an observation that Lakoff explores theoretically--i.e., that the "LOCATION" and "OBJECT" metaphor themes make other, richer metaphors possible. ferences.

${ }^{2}$ This organizing role of primitives is similar to the role of Schank's (1975) primitive ACTs in organizing nonmetaphorical in- 
A further observation about the basic character of the "OBJECT" and "LOCATION" metaphors concerns other attempts to describe analytically what verbal concepts mean. Verb descriptions proposed in various disciplines often involve units such as "objects" and "relations" (sometimes expressed as various kinds of "cases" or labeled arrows). In MAP, the formulation of these units in terms that are explicitly spatial or locative is an acknowledgment of the way we metaphorically extend object construction and location to talk about concepts in various nonspatial domains. As these structures represent verbal states with OBJECT and LOCATION "slots" or "roles" to be filled by nouns representing dependent objects, they could be viewed as abstracted conceptual case configurations. Because specific domains are "factored out" of the structures, ${ }^{3}$ this system unifies some of Fillmore's (1968) cases; it also unifies Schank's (1975) conceptual cases and some of his primitive ACTs/STATEs, most notably his obviously analogous ACTs of TRANSition. In contrast to the representations of Fillmore and Schank, these structures are extensible, that is, they can consistently represent part of the common ground of a verbal metaphor.

Such abstract descriptions constitute a simple formalization of the ways that our language serves as a spatial or object-oriented filter for the world. (Sentences in which this spatial orientation is particularly obvious are provided in Reddy's (1979) discussion of the "conduit metaphor.") The fact that a verbal structure can be extended between conceptually different domains means that it serves as a filter for viewing all those domains. These spatial filters may not seem to get at the precise meaning of a concept in a nonspatial target domain. However, as one soon finds out in the course of computational efforts, there is often no way to express even a relatively mundane cross-modal metaphor with all its subtleties (such as "He vacuumed up the ideas") in terms that are truly literal for the target domain. We can only reduce such metaphors to more basic metaphors or filters that appear to be literal.

To summarize, the emergence of the "OBJECT" and "LOCATION/CONTAINER" metaphors in the development of Lakoff's theory has an interesting correspondence with the computational representation choice used in MAP. Lakoff's observations about the dependence of some conceptual metaphors on more basic conceptual metaphors should be of interest to designers of computational models of language that are intended to be thought based rather than word based. In MAP, the criterion of generality has led to the adoption of abstract structures implicitly based on the "OBJECT" and "LOCATION" metaphors. These verbal-concept structures can be viewed as conceptual metaphors that filter conceptually different domains, thereby mediating comprehensible extensions between the domains. If the assumption underlying this approach is correct, then the "OBJECT" and "CONTAINER/LOCATION" metaphors may have an even wider significance in the human conceptual system than Lakoff suggests.

${ }^{3}$ From a linguistic perspective, this kind of analogy-oriented approach is also found in Jackendoff's (1976) verb representations. 


\section{REFERENCES}

Carbonell, J. (1982). Metaphor: An inescapable phenomenon in natural-language comprehension. In W. Lehnert \& M. Ringle (Eds.), Strategies for natural language processing (pp. 415-434). Hillsdale, NJ: Lawrence Erlbaum Associates, Inc.

Fillmore, C. (1968). The case for case. In E. Bach \& R. Harms (Eds.), Universals in linguistic theory (pp. 1-88). New York: Holt, Rinehart \& Winston.

Jackendoff, R. (1976). An explanatory semantic representation. Linguistic Inquiry, 7, 89-150.

Lakoff, G. (1986). A figure of thought. Metaphor and Symbolic Activity, 1, 215-225.

Lakoff, G., \& Johnson, M. (1980). Metaphors we live by. Chicago: Chicago University Press.

Reddy, M. (1979). The conduit metaphor--A case of frame conflict in our language about language. In A. Ortony (Ed.), Metaphor and thought (pp. 284-324). Cambridge, England: Cambridge University Press.

Russell, S. Weber (1976). Computer understanding of metaphorically used verbs. American Journal of Computational Linguistics, Microfiche 44.

Russell, S. Weber (1986). Information and experience in metaphor: a perspective from computer analysis. Metaphor and Symbolic Activity, 1, 227-270.

Schank, R. (1975). Conceptual information processing. Amsterdam, Netherlands: North Holland. 